\title{
Size and composition measurements of background aerosol and new particle growth in a Finnish forest during QUEST 2 using an Aerodyne Aerosol Mass Spectrometer
}

\author{
J. D. Allan ${ }^{1,2}$, M. R. Alfarra ${ }^{1, *}$, K. N. Bower ${ }^{1}$, H. Coe $^{1}$, J. T. Jayne ${ }^{3}$, D. R. Worsnop ${ }^{3}$, P. P. Aalto ${ }^{4}$, M. Kulmala ${ }^{4}$, \\ T. Hyötyläinen ${ }^{5}$, F. Cavalli $^{6}$, and A. Laaksonen ${ }^{7}$ \\ ${ }^{1}$ School of Earth, Atmospheric \& Environmental Science, University of Manchester, UK \\ ${ }^{2}$ Distributed Institute for Atmospheric Composition, NERC Centres for Atmospheric Science, UK \\ ${ }^{3}$ Aerodyne Research Inc., Billerica, MA, USA \\ ${ }^{4}$ Department of Physical Sciences, University of Helsinki, Finland \\ ${ }^{5}$ Department of Chemistry, University of Helsinki, Finland \\ ${ }^{6}$ Institute of Atmospheric Sciences and Climate, Consiglio Nazionale delle Ricerche, Bologna, Italy \\ ${ }^{7}$ Department of Applied Physics, University of Kuopio, Finland \\ *now at: Laboratory for Atmospheric Chemistry, Paul Scherrer Institut, Switzerland
}

Received: 1 August 2005 - Published in Atmos. Chem. Phys. Discuss.: 14 September 2005

Revised: 12 December 2005 - Accepted: 30 December 2005 - Published: 6 February 2006

\begin{abstract}
The study of the growth of nucleation-mode particles is important, as this prevents their loss through diffusion and allows them to reach sizes where they may become effective cloud condensation nuclei. Hyytiälä, a forested site in southern Finland, frequently experiences particle nucleation events during the spring and autumn, where particles first appear during the morning and continue to grow for several hours afterwards. As part of the QUEST 2 intensive field campaign during March and April 2003, an Aerodyne Aerosol Mass Spectrometer (AMS) was deployed alongside other aerosol instrumentation to study the particulate composition and dynamics of growth events and characterise the background aerosol. Despite the small mass concentrations, the AMS was able to distinguish the grown particles in the $<100 \mathrm{~nm}$ regime several hours after an event and confirm that the particles were principally organic in composition. The AMS was also able to derive a mass spectral fingerprint for the organic species present, and found that it was consistent between events and independent of the mean particle diameter during non-polluted cases, implying the same species were also condensing onto the accumulation mode. The results were compared with those from offline analyses such as GC-MS and were consistent with the hypothesis that the main components were alkanes from plant waxes and the oxidation products of terpenes.
\end{abstract}

Correspondence to: J. D. Allan

(james.allan@manchester.ac.uk)

\section{Introduction}

The processes governing the formation of new aerosol particles are a very important aspect of atmospheric science to understand and quantify. For instance, the number concentrations of atmospheric particles affects the microphysics of clouds, which may affect their rainfall, lifetime and optical properties and in turn, global climate (Penner et al., 2001; Twomey, 1977). In addition to mechanical and combustion processes, new particles can be created from the nucleation of gas phase species (Kulmala et al., 2000; Kulmala, 2003). These events have been observed in a variety of environments worldwide and may be a significant factor in the repopulation of particle numbers lost through deposition. Typically, these particles are measured in high numbers $\left(\sim 10^{5} \mathrm{~cm}^{-3}\right)$ at their source and occur in discrete 'bursts'. There are thought to be many different precursor species responsible, specific to each environment, which can be of either natural or anthropogenic origin (Kulmala et al., 2004b).

In addition to the processes governing the initial formation of the particles, the mechanisms behind the subsequent growth must also be understood and quantified if they are to be considered in regional and global climate models, as the new particles must grow to significant sizes $\left(\sim 10^{2} \mathrm{~nm}\right)$ if they are to affect the optical properties of the atmosphere and clouds. Also, smaller particles have very high Brownian velocities, so would quickly diffuse onto available surfaces and therefore have short atmospheric lifetimes if the growth processes were absent. Particle coagulation is one process responsible, but the addition of extra mass through gas to

(C) 2006 Author(s). This work is licensed under a Creative Commons License. 
particle conversion is also important. The gas species responsible may or may not be the same ones that are responsible for the initial nucleation.

The study of freshly-nucleated particles is inherently difficult due to their small size. The direct observation of the number and size of particles less than around $2.5 \mathrm{~nm}$ in diameter is currently impossible with commercially-available instrumentation. Similarly, the study of the chemical composition of these particles is limited by the small amounts of matter they posses. The composition of atmospheric particles can be studied by first collecting them in bulk on filter or impactor substrates for offline analysis. While these techniques permit the use of many powerful analytical procedures, limitations are imposed by the need to collect a significant amount of particulate matter during sampling, depending on the analytical technique used. This, in turn, means that the samplers must be operated for several hours continuously, which is undesirable for the study of dynamic systems such as this. Also, while cascade impactors offer some size-resolved data, the resolution is generally poor compared to that possible with dedicated sizing instrumentation. It is possible to collect particles as small as $10 \mathrm{~nm}$ with suitable low-pressure impactors, although concentrators must be used to collect large enough samples, even when working in a polluted environment (Geller et al., 2002).

The chemical composition of growing ultrafine particles has been measured previously using aerosol mass spectrometry, although in different environments. Using an Aerodyne Aerosol Mass Spectrometer (AMS), Zhang et al. (2004a) were able to show that the composition of the growing particles was predominantly sulphuric acid during the earliest observable stages of formation events in Pittsburgh in September 2002. The particles in more advanced stages of growth showed amounts of ammonium and later still, organic matter was found to be present. The composition of ultrafine particles during nucleation events in Atlanta has also been studied using a Thermal Desorption Chemical Ionization Mass Spectrometer in series with Differential Mobility Analysers (Smith et al., 2005), who also concluded that ammonium sulphate was the principal condensing species.

Nucleation events have also frequently been observed in non-polluted environments, such as the Hyytiälä forestry research station in southern Finland (e.g. Kulmala et al., 2001). The compositions of growing particles in a forested environment such as this are expected to be different to those in urban environments. The chemical analysis of growth event aerosols from a previous study at Hyytiälä was presented by Mäkelä et al. (2001), who analysed samples collected with cascade impactors using ion chromatography (IC). The analysis of samples taken on days where nucleation took place showed little significant difference to the samples from other days, except for extra amounts of methanesulphonic acid and dimethylamine. However, it may be that much of the matter that made up the growing particles were not be observable using IC, through either insolubility or chemical instability.
The Quantification of Aerosol Nucleation in the European Boundary Layer (QUEST) 2 field campaign, which took place during March and April 2003, was an intensive study into these phenomena at Hyytiälä. It is thought that in this particular environment, the biogenic VOCs and their oxidation products are responsible for the growth of the particles, although the initial formation is thought to happen though the nucleation of sulphuric acid with water and/or ammonia (Kulmala et al., 2000). For a detailed study into the initial nucleation and early stages of growth during this study, the reader is directed to Kulmala et al. (2004a). Each nucleation burst normally occurred during the morning of a given day and the particles typically grew in size during the following hours into the evening and night, providing no air mass changes occurred. This did not happen every day, meaning that each day could be classed as either an "event" or "nonevent" day. The event days at Hyytiälä are mostly confined to the spring and autumn months. During the campaign, an extensive suite of particle, gas and meteorological instrumentation was deployed, which included an AMS.

\section{Experimental}

In addition to the AMS, other aerosol samplers were deployed for offline mass and chemical characterisation. In particular, some 5-stage Berner low-pressure impactors (Berner et al., 1979) were deployed by the CNR Bologna group. Each substrate set collected aerosol from multiple event or nonevent days, in order to collect as much mass of a particular aerosol type as possible. Samples collected using these were either weighed for gravimetric mass measurement or dissolved in water for IC and water soluble organic carbon (WSOC) analysis. More details on this work is presented in Cavalli et al. (2005). Aerosols were also collected on quartz filters using high-volume samplers for offline analysis at the Department of Chemistry, Helsinki, using techniques such as gas chromatography-mass spectrometry (GCMS). For more information on the sampling methodology, the different types of organic analyses performed on the filter samples and the results obtained, the reader is directed to Anttila et al. (2005), Shimmo et al. (2004) and Rissanen et al. (2006). Some of the particle physical data used in this publication were derived from instrumentation permanently deployed as part of the collocated Station for Measuring Forest Ecosystem-Atmosphere Relations (SMEAR) 2, in particular the Differential Mobility Particle Sizer (DMPS) system (Aalto et al., 2001), which was used to count and size the particles between approximately 3 and $1000 \mathrm{~nm}$ on $10 \mathrm{~min}$ intervals.

The AMS, its operation and data analysis techniques are dealt with in detail elsewhere (Allan et al., 2003a; Allan et al., 2004a; Jayne et al., 2000; Jimenez et al., 2003), but some specific modifications that were made are described below. The instrument thermally flash vaporises the non-refractory 
component of the submicron particles and analyses the resultant vapours in situ using $70 \mathrm{eV}$ electron ionisation (EI) and a quadrupole mass spectrometer. The data are processed to derive quantitative mass concentrations of various components such as sulphate, nitrate, organics and ammonium. It also uses the aerodynamic sizing of selected $\mathrm{m} / \mathrm{z}$ channels to deliver these data as a function of particle diameter. In addition to the main inorganic $m / z(16,30,36,48,64)$ a selection of principally organic $m / z$ were selected $(27,43,44,55,57,67$, 77, 91).

By inspecting the mass spectra, it is also possible to derive information regarding the overall nature of the organic fraction. While, the mass spectra produced by the instrument have been shown to be largely comparable with those in $70 \mathrm{eV}$ mass spectral libraries such as NIST (2003), some differences introduced by the temperature of the vaporiser. These can occur through two mechanisms: One is that the extra heat imparted onto the molecules during vaporisation may increase the amount of internal energy during ionisation, increasing the likelihood of bonds breaking; the second effect is that some species may fragment on the surface of the vaporiser during vaporisation, so the vapour molecules ionised by EI are chemically different from the parent species. For simpler organic molecules, the locations of the peaks within the spectra are unchanged, but first effect manifests as a bias in the relative peak sizes towards the low $\mathrm{m} / \mathrm{z}$ peaks in the spectrum (note that PAHs are a known exception to these, due to their extra molecular stability). When more complex molecules are studied, in particular oxygenated, multifunctional species, the second effect causes the mass spectrum to be dominated by smaller ions such as $\mathrm{CO}_{2}^{+}$(Alfarra, 2004; Silva et al., $2006^{1}$ ). Note that neither effect changes the number of ions produced, therefore the instrument's quantitative capability is maintained.

While the mass spectrometric evaluation of the aerosol ensemble does not yield as much information as more specialist offline analytical procedures, the fact that it is performed in real time and in situ means that time resolutions of minutes are possible and artefacts associated with gas phase interchanges and handling are eliminated. Also, the sizeresolving capability allows the particle chemical compositions to be assigned to individual particle modes identified using sizing equipment such as the DMPS. The AMS data is capable of studying the dynamic chemical composition of the particles during the growth stages as a function of particle size with high resolution, which can in turn reduce the ambiguity when linking the accurate sizing and number data produced by the dedicated sizing instrumentation and the detailed chemical composition data derived from the various offline analyses.

${ }^{1}$ Silva, P., Canagaratna, M., Jimenez, J. L., Jayne, J. T., Kolb, C. E., Davidovits, P., and Worsnop, D. R.: Quantitative Analysis of Non-refractory Fine Particles Using Aerosol Mass Spectrometry, Aerosol Sci. Technol., in preparation, 2006.
The instrument uses an aerodynamic lens to focus the particles as they are introduced into the instrument (Liu et al., 1995a, 1995b), before the majority of the gas phase material is skimmed off and the aerosol beam introduced into the detection region. Aerodynamic lenses are capable of focussing particles with $100 \%$ efficiency over a given range of aerodynamic diameters, in this case 30 to $700 \mathrm{~nm}$ (Zhang et al., 2002, 2004b). Particles smaller than $30 \mathrm{~nm}$ do not posses enough inertia to be focussed correctly, so the instrument is unable to study those in the early stages of the growth processes. Another limitation is imposed by the signal to noise ratios of the processed data, which are directly linked to the total amount of mass the particles possess and the sensitivity of the mass spectrometer. This factor also hampers the study of the small particles, although the temporal averaging of the data mitigates this.

To complement the standard deployment of the AMS, the instrument was also fitted with additional equipment to identify and hopefully quantify particle collection biases. In a previous experiment during ITCT $2 \mathrm{~K} 2$ at Trinidad Head, California, 2002, it was noted that the collection efficiency of the instrument varied as a function of the relative humidity of the aerosol sampled (Allan et al., 2004b). The speculation made at the time was that the effloresced particles were irregularly shaped and as a result, were forming a more divergent beam in the aerodynamic lens through lift forces that in turn resulted a smaller number being detected.

To probe this behaviour further, a temperature control system similar in principle to that used during ITCT $2 \mathrm{~K} 2$ was deployed, although instead of using water from a temperature-controlled bath in a jacket around the AMS inlet, a Peltier thermoelectric cooler (Marlow Industries model AT12-6, Dallas, TX, USA) was used to control the inlet temperature directly (Allan, 2004). The inlet assembly around the critical orifice used to control the flow was encased in a small copper block to which the Peltier cooler was attached in a compression fitting. The Peltier cooler itself was operated using a programmable controller (Oven Industries model 5C7-362, Mechanicsburg, PA, USA), employing a feedback loop connected to a bead thermistor located next to the pinhole. The setpoint was continuously calculated and updated using a computer and matched to a relative humidity, based on the ambient temperature and humidity measurements provided by a solid-state probe (Rotronic model Hygroclip SC05, Crawley, West Sussex, UK). For the first half of the experiment, the inlet was at cabin temperature (which was generally much larger than ambient), while in the latter half, the inlet temperature was matched to $90 \% \mathrm{RH}$ above water.

In addition to the temperature control, a beam probe was installed in the instrument's chamber immediately prior to the detection region. This consisted of a wire that was moved in and out of the aerosol beam by a servo motor, in effect an automated version of the probe used by Jayne et al. (2000). This operated continuously during sampling, 


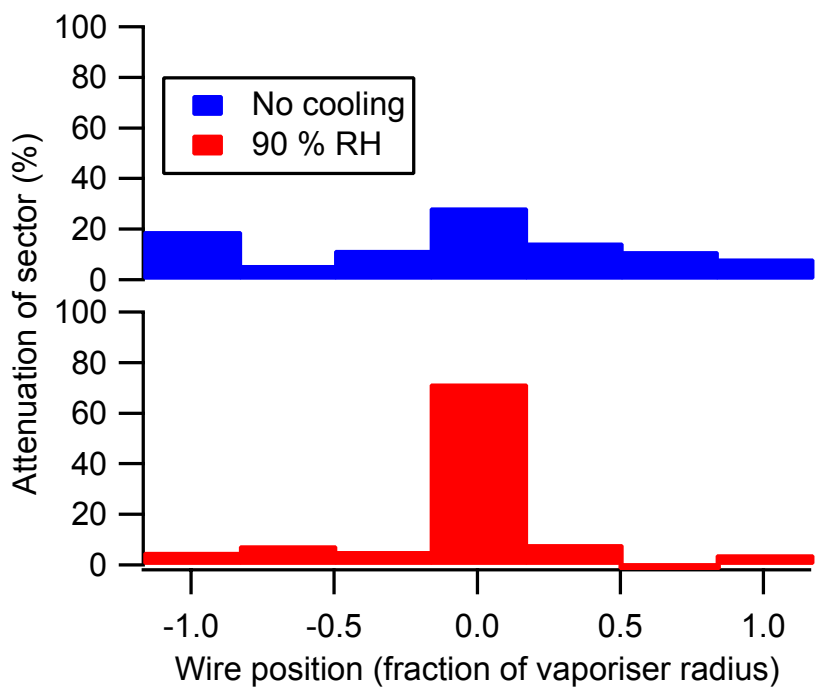

Fig. 1. Beam profiles with and without inlet cooling, based on the measured sulphate mass concentrations with and without the wire interposed in the particle beam. The attenuations are normalised to $100 \%$. Both graphs were generated from data taken from periods when accumulation mode particles (mass mode at around 300$400 \mathrm{~nm}$ ) dominated the mass concentrations.

alternating between a fully open position and one of seven blocking positions every two minutes (the "unblocked" data were the only ones used for the standard analyses). By studying the reduction in the measured signal as a function of wire position, a horizontal profile of the aerosol beam could be generated. When comparing the attenuations of the different wire positions for the low (cabin temperature) and high (90\%) humidity sampling scenarios, it does appear that the humidity does have an effect on the divergence (Fig. 1). At high humidity, a large fraction of the particles are confined within the centre region of the particle beam, while at lower humidities, they are more spread out, showing that phase changes in the particles can cause a degree of beam divergence. The next stage is to quantify what overall effect this has on the instrument detection efficiency. To this end, recent work has been undertaken at the University of Colorado at Boulder to model the response of the beam probe technique to theoretical particle beams of varying divergence (Huffmann et al., 2005). According to this work, for a noticeable fraction of particles to miss the vaporiser, the beam attenuation at the centre wire position must be around $15 \%$ or less for a $0.39 \mathrm{~mm}$ wire. As Fig. 1 shows, the attenuation in the dry case is around $30 \%$ for a $0.5 \mathrm{~mm}$ wire, which, as a low estimate, would translate as an attenuation of $23 \%$ for a $0.39 \mathrm{~mm}$ wire. This means that while there is a degree of beam divergence when studying the ambient particles in this case, the divergence itself does not significantly affect the instrument collection efficiency.

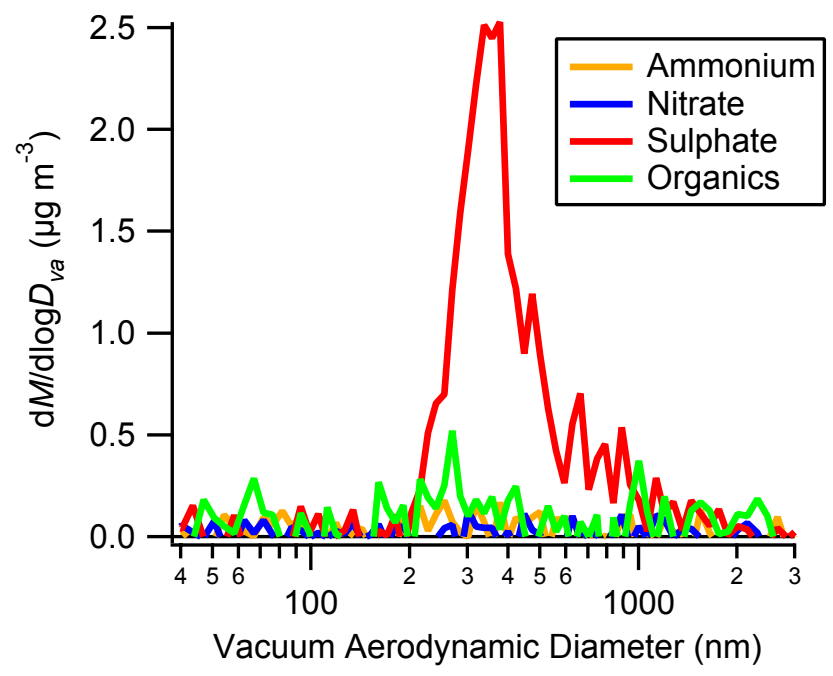

Fig. 2. Mass distribution from a period of arctic influence (20 March).

More recently, results obtained by Aerodyne Research Inc. and Boston College using an in situ light scattering probe when sampling ambient aerosols (Cross et al., 2004), seem to suggest that beam divergence is not the main reason for the loss of dry particles. The current favoured hypothesis is that dry, solid particles are more likely to "bounce" when they impact on the vaporiser and not be detected, whereas deliquesced, liquid particles will stick and not be lost. The effect on the particle collection efficiency is increased to unity when the inlet is chilled and the particles deliquesce, which is consistent with the observations of Allan et al. (2004b). Some water will inevitably be lost in the low pressure of the aerodynamic lens (Buzorius et al., 2002), but Allan et al. (2004b) found that most particles over around $100 \mathrm{~nm}$ in diameter retained at least some water until detection. This phenomenon is currently the subject of much investigation and will be discussed in future technical publications. For the purposes of this paper, the collection efficiency has been assumed to be 0.5 while the inlet was at low humidity and 1 at high humidity. This is in line with previous comparisons where it has been found that sampling without humidity or temperature control normally results in an overall heating of the aerosol relative to ambient, drying the particles and giving and collection efficiency of 0.5 , whereas sampling through a chilled line has given a collection efficiency of 1 (e.g. Allan et al., 2004b; Drewnick et al., 2003).

\section{Results}

There were many event days witnessed during the QUEST 2 campaign, as classified by the DMPS data. One of the most significant factors noted to affect the behaviour on any one particular day is the history of the air mass prior to arrival 


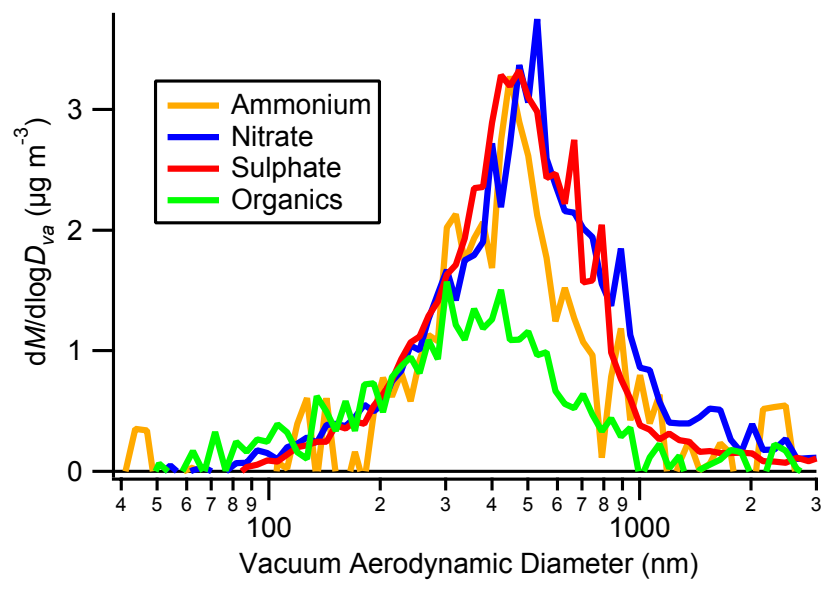

Fig. 3. Mass distribution from a polluted continental airmass (29 March).

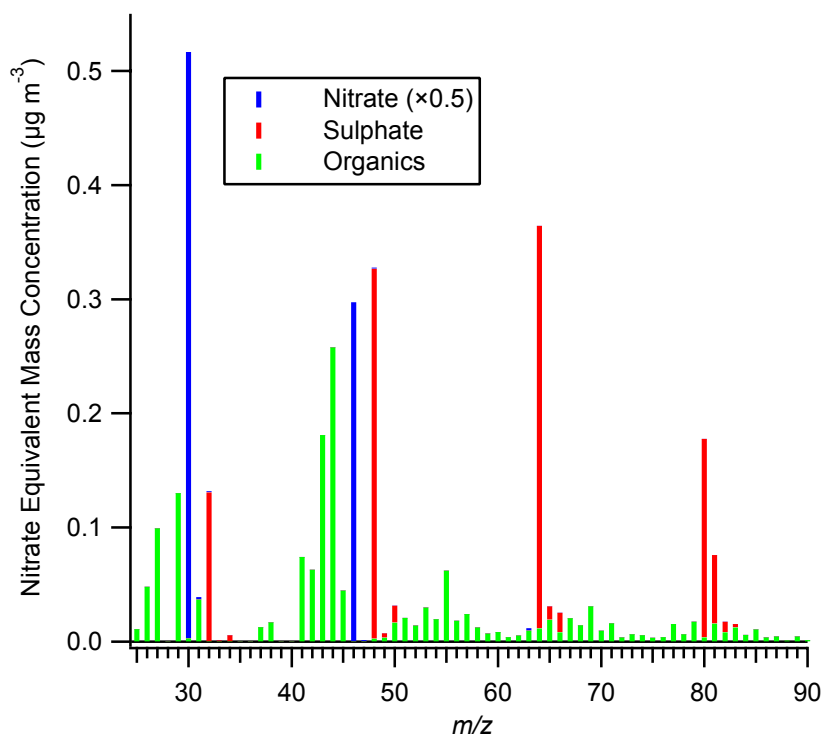

Fig. 4. Mass spectral signature for nitrate, sulphate and organics during a period of continental influence. The nitrate values have been halved for clarity. This pattern is typical of regional pollution observed using the AMS.

at the site. Typically, a nucleation event is more likely to occur if the air mass originated from arctic regions in the north, which is consistent with previous observations at this site. This would stand to reason, as lower background particle numbers are typically measured under these conditions, which results in a lower available surface area and conceptually a smaller sink for the precursor gases. There are other potential reasons in addition to this, such as the lower temperatures causing gases to partition into the particle phase and a reduced mixing height. For a more detailed discussion on this topic, the reader is directed to Nilsson et al. (2001).

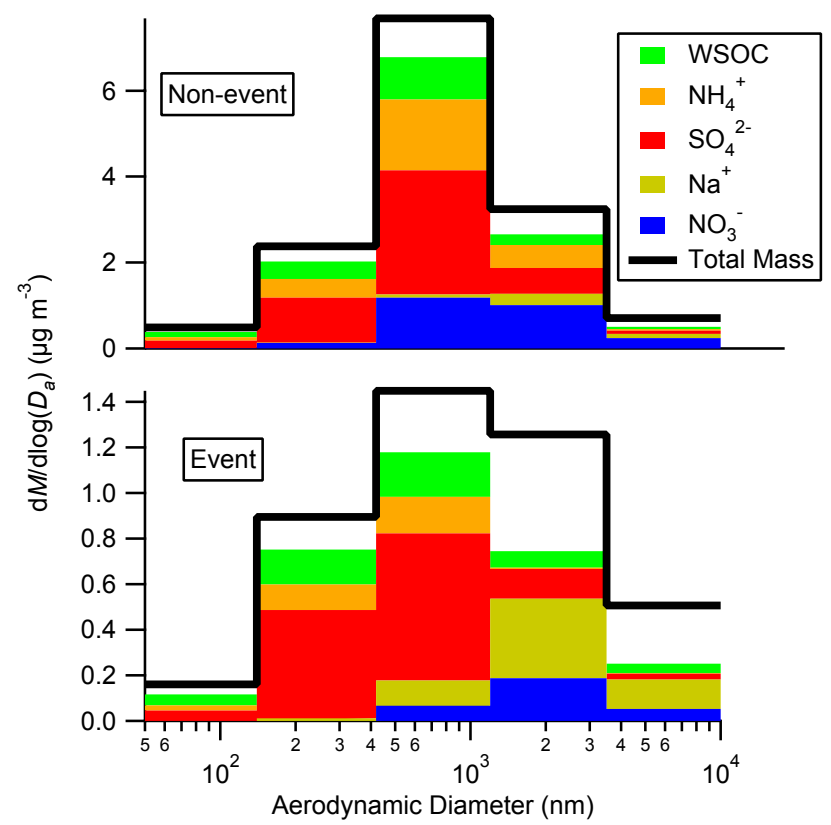

Fig. 5. Ion chromatography, water soluble organic carbon (WSOC) and gravimetric mass data from Berner impactor samples, averaged over all event and non-event days.

The AMS was able to characterise both the size and composition of the particles during the various conditions. For a more detailed study of the origins of the air masses experienced during QUEST 2, the reader is directed to Petäjä et al. (2005). Typically, when the site was subjected to northern air masses as shown by back trajectories (Draxler and Rolph, 2003), the overall mass concentrations of the background aerosol were low, with the particles existing in a single accumulation mode, mainly composed of sulphate (Fig. 2). During the majority of these cases, the measured amounts of ammonium were not sufficient to fully neutralise the particles, therefore they were mainly acidic in nature. These were the conditions typical of event days. Conversely, when the site was subjected to air from continental Europe (the conditions which favoured non-event days), the concentrations were much higher, with the particles containing significant amounts of sulphate, organic matter, ammonium and frequently nitrate (Fig. 3), the latter being a good indication of $\mathrm{pH}$ neutrality as nitrate will partition into the gas phase as nitric acid from an acidic particle. The organic mass spectral fingerprint observed during periods of continental influence has its primary peak at $m / z 44$, with other peaks at 43 and 55 (Fig. 4). This signature is indicative of highly oxidised organic species and is considered typical for processed particulate matter observations with the AMS. The same pattern has been observed in other areas influenced by non-local organic sources (e.g. Alfarra et al., 2004; Topping et al., 2004). Other tracers for anthropogenic emissions were also detected under these conditions using offline techniques, 
(a) AMS Organics
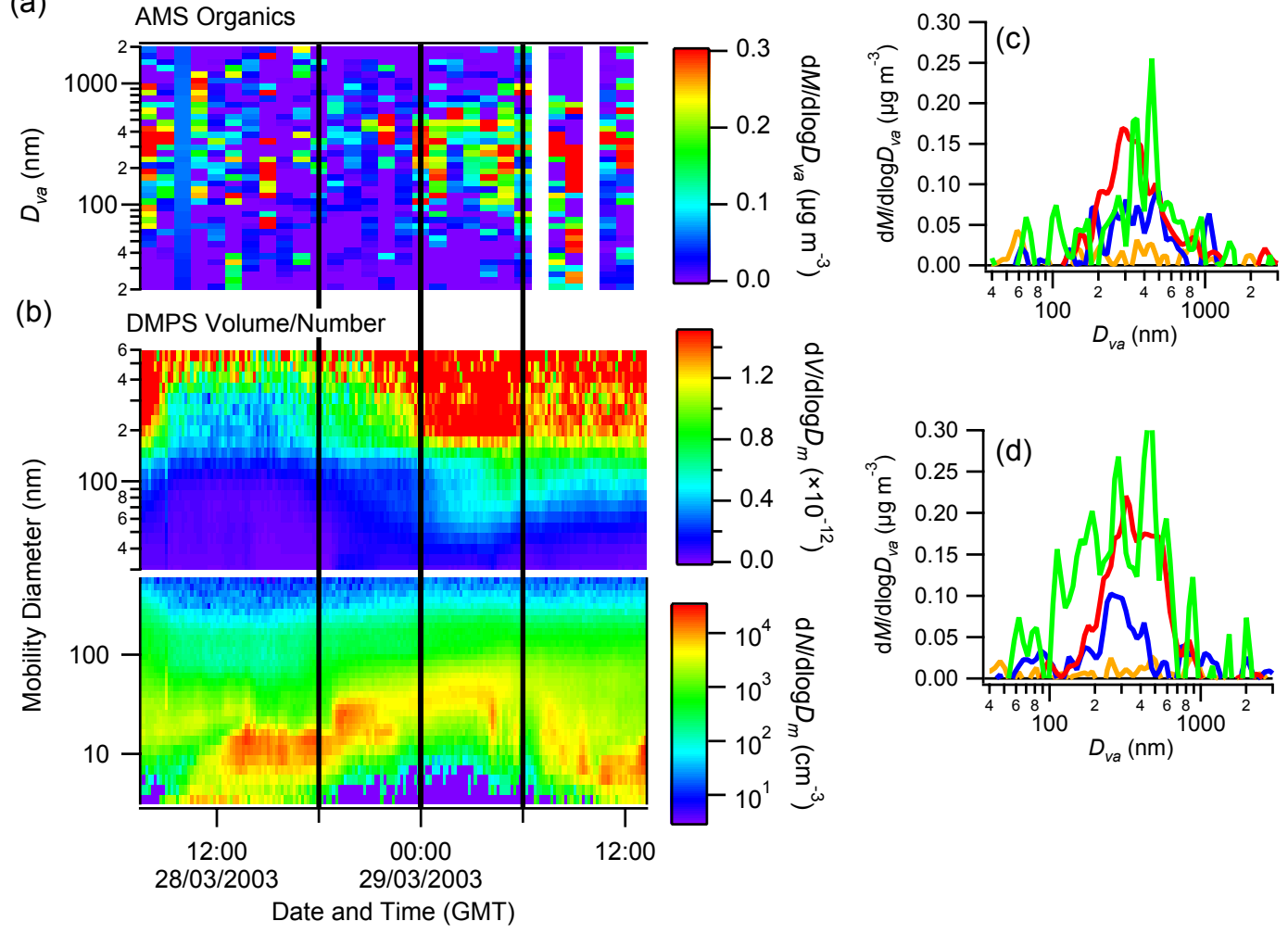

Fig. 6. The 28 March nucleation and growth event. (a) is the AMS-measured organic mass distribution, while (b) is the DMPS-measured volume and number concentrations. (c) is the AMS distribution from 18:00 to 00:00 GMT, while (d) is from 00:00 to 06:00 the following day. These periods are indicated by the black lines on (a) and (b) for convenience. Note that the AMS data in (a) have been averaged to reduce the amount of noise, for the sake of clarity.

for example polycyclic aromatic hydrocarbons and elemental carbon (Shimmo et al., 2004; R. Janson, Stockholm University, personal communication, 2005).

These assessments are in general agreement with the gravimetric mass and ion chromatography analyses of cascade impactor samples, collected over multiple event and non-event days, which generally speaking, corresponded to arctic- and continental-influenced days respectively. These too show low mass concentrations, being sulphate-dominated in the accumulation mode during the event days while there is more mass and a greater abundance of ammonium and nitrate. The accumulation mode peak normally occurred within the $420<D_{a}<1200 \mathrm{~nm}$ impactor stage (Fig. 5).

During a typical nucleation day, several hours' worth of growth were needed before the new particles were observable with the AMS. Generally speaking, the particles exhibited a clear presence in the mass size distributions in the late afternoon of an event day, forming a distinct Aitken mode, and became bigger during the night. Under these situations, while the new particles were several hours old, the site has a very large forested fetch to the north, so the particles sampled can be considered representative of the environment, providing that there is no change in wind direction during an event day large enough to result in a different air mass or emissions footprint being sampled.

The grown particles were exclusively organic in nature during the early stages of their evolution, although sometimes they would become accompanied by nitrate or sulphate in the late evening. There was almost always be a detectable accumulation mode present during the day, although the amount of mass this represented varied between the different days. Sometimes, the Aitken mode, while distinct in the DMPS number distributions, would be dwarfed by the accumulation mode in the AMS mass distributions. Note that the term "Aitken mode" is applied very loosely within this paper; very often, a particle population that has a distinct mode in the $10<D_{m}<100 \mathrm{~nm}$ regime in the DMPS number distributions (the most common definition for an Aitken mode) can often manifest as a mode with a peak of a larger diameter $\left(D_{v a}<200 \mathrm{~nm}\right)$ in the AMS mass distributions. This is due to the conversion of electromobility to vacuum aerodynamic diameters and the mapping of aerosol particle number distributions to volume (DeCarlo et al., 2004). However, during these measurements, the mode was normally distinct from the AMS-measured accumulation mode, whose peak was normally of a $D_{v a}$ of greater than $300 \mathrm{~nm}$. 

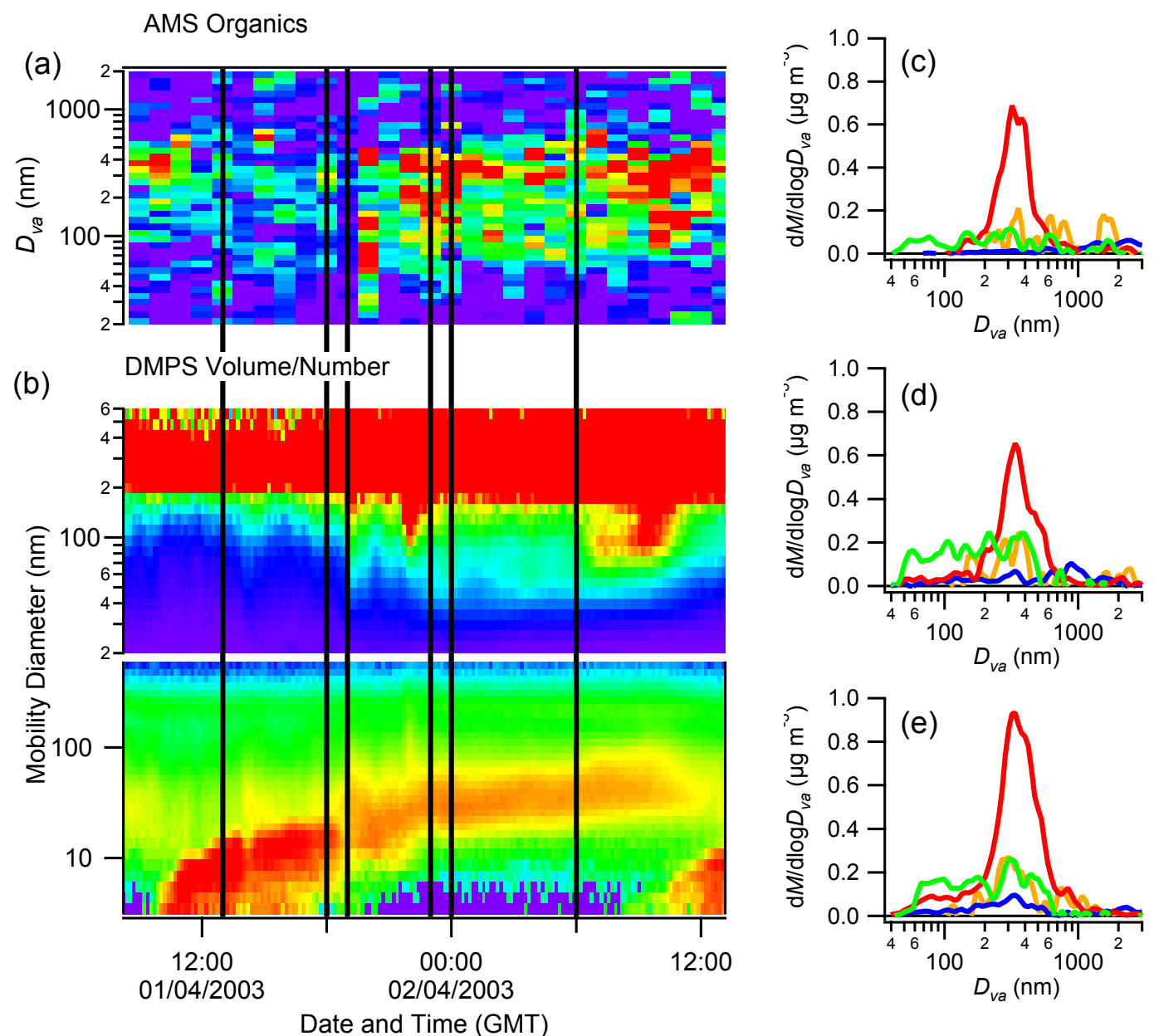

Fig. 7. The 1 April growth event as observed by the AMS (a) and DMPS (b). The colour scales are identical to those used in Fig. 6. Distributions (c), (d) and (e) are from 13:00-18:00, 19:00-23:00 and 00:00-06:00 GMT respectively. Note that the composition in the Aitken mode is partly inorganic during the later stages.

As an example, the data from two case study event days (28 March and 1 April) are shown (Figs. 6 and 7), compared to the DMPS number concentrations (the data from 25 March, another day designated as a QUEST case study, are unfortunately unsuitable for AMS analysis, as there was an air mass change at around 23:00 GMT). In the case of 28 March, back trajectories indicated the air originated from the northwest, whereas on 1 April, it was from a more northerly direction. In both cases, the amount of organic matter in the smaller sizes $(<100 \mathrm{~nm})$ increased in the later stages of growth, relative to the earlier stages. While the mass concentrations are small, it is important to note the difference in how the organic matter is distributed amongst the particles sizes compared to sulphate. While sulphate tends to be exclusively contained within the accumulation mode, the organics have a significant presence in the Aitken mode. In the case of 1 April, the smaller particles also acquired some inorganic mass in the form of sulphate in the later stages of growth.
While the growth events were qualitatively detectable, the mass concentrations and therefore signal to noise ratios were much lower than in polluted environments. As a result, the most reliable results are derived after averaging the data from multiple event days, as identified using DMPS data. The organic mass spectral fingerprint produced by averaging all of the data from event days was fairly consistent between events, although it was unlike any mass spectra observed previously in other environments. The relative peak sizes of the fingerprint was invariant of whether the organic distribution was Aitken or accumulation mode dominated (this was found to be true for a range of cases, exhibiting organic mass modes from 80 to $400 \mathrm{~nm}$ ). The base peak was consistently at $\mathrm{m} / z$ 43 , a very common organic peak in ambient aerosols (typically $\mathrm{C}_{3} \mathrm{H}_{7}^{+}, \mathrm{C}_{2} \mathrm{H}_{3} \mathrm{O}^{+}$or their isomers), which can be indicative of both aliphatic and oxidised features. There were many peaks present from the $\mathrm{C}_{n} \mathrm{H}_{2 n+1}^{+}$and $\mathrm{C}_{n} \mathrm{H}_{2 n-1}^{+}$series (e.g. 55, $57,69,71)$ which can indicate the presence of heavily saturated and non-oxidised hydrocarbon-like organic species, 


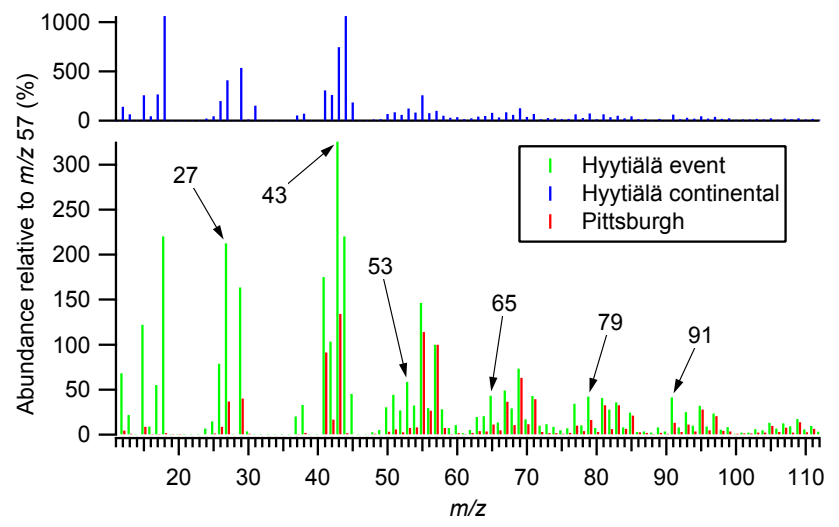

Fig. 8. Comparison between the organic mass spectral signatures of a growth event at Hyytiälä and primary traffic emissions extracted from ambient sampling in Pittsburgh (Zhang et al., 2005). These are also compared with a spectrum from the continentally-influenced period shown in Fig. 4. The spectra are presented relative to $\mathrm{m} / \mathrm{z}$ 57 , the largest aliphatic peak that does not receive significant contributions from other known atmospheric organic species.

such as alkanes (McLafferty and Turecek, 1993). This pattern in AMS data has been observed many times before, in particular when sampling in urban environments where unburned lubricating oils dominate the organics in the smaller particles (e.g. Alfarra et al., 2004; Allan et al., 2003b; Canagaratna et al., 2004). This is highlighted in Fig. 8, where the signature obtained in Hyytiälä is compared with an urban primary organic spectrum from Pittsburgh, extracted numerically using a form principle component analysis (Zhang et al., 2005). However, additional peaks were present with sizes relative to the other peaks that had not been observed before, such as $m / z 50,51,53,65,77,79$ and 91 . The prevalence of these peaks over the corresponding aliphatic peaks could potentially be associated with a low hydrogen to carbon ratio in the parent organic molecules relative to alkanes, possibly as a result of unsaturated and/or cyclic features. Also, several of the lower mass peaks, such as $m / z 12,15,27$ and 29, were significantly elevated relative to the other peaks.

The component reported as 'nitrate' using the standard AMS analysis techniques is derived from the signals at $m / z$ 30 and 46 (Allan et al., 2003a). While this is an accurate description for most of the data collected using the AMS, in some cases, other species are thought to be responsible for the signals. In polluted environments in particular, $m / z 30$ signals are associated with the $\mathrm{NO}^{+}$fragment from $\mathrm{NH}_{4} \mathrm{NO}_{3}$ and are usually accompanied with a corresponding signal at $m / z 46\left(\mathrm{NO}_{2}^{+}\right)$, with a ratio of around 2.5:1. This behaviour was seen in the accumulation mode during this study during polluted periods, which is consistent with $\mathrm{NH}_{4} \mathrm{NO}_{3}$. However, there were several instances during this campaign when an $m / z 46$ signal was not present when a large signal at $m / z, 30$ was. When looking at the size-resolved data, some of the excess $m / z 30$ signal was seen in the coarse

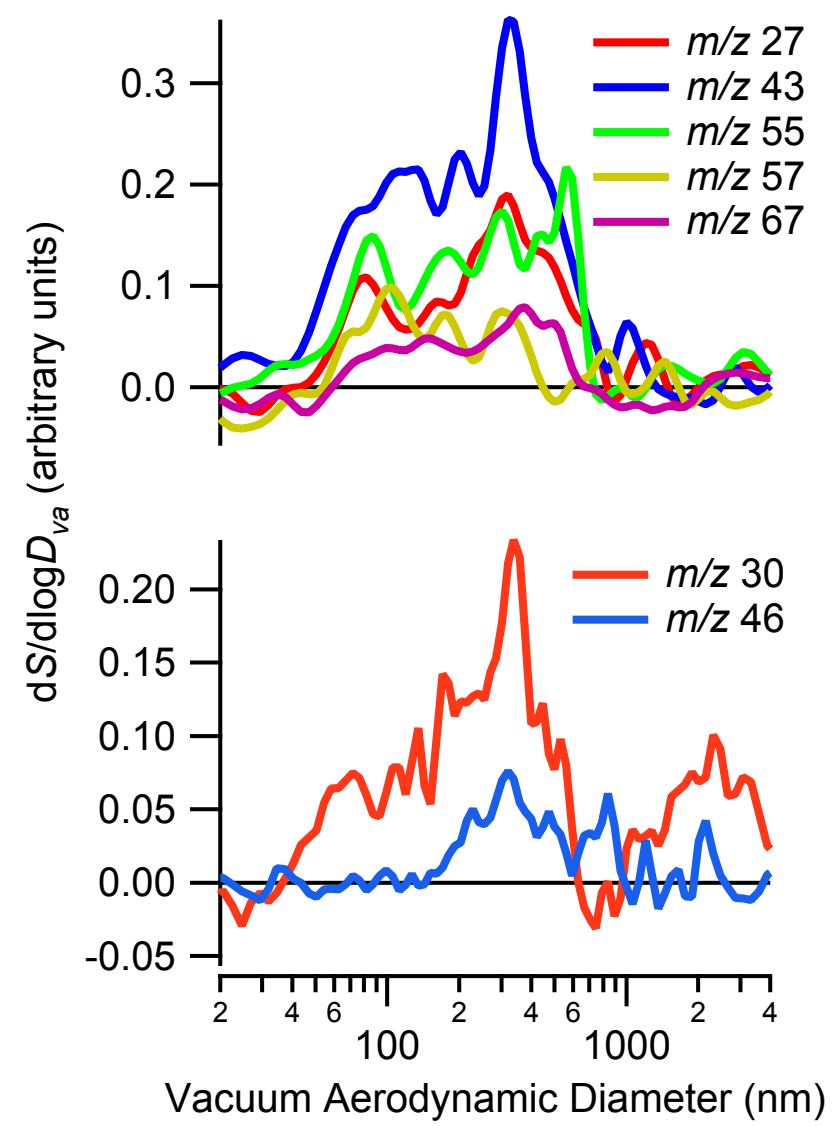

Fig. 9. Graph comparing the different $\mathrm{m} / \mathrm{z}$ signals from the period of 00:00 to 06:00 GMT on 2 April, during the later stages of a growth event. The top graph shows the organic signals, which are smoothed for clarity and show their presence in both the Aitken and accumulation modes. The bottom graph shows the two $m / z$ channels traditionally associated with nitrate (30 and 46) The accumulation mode $(150-600 \mathrm{~nm})$ signal ratios are typical of ammonium nitrate, while the coarse mode $(>1 \mu \mathrm{m})$ signal is probably due to sodium nitrate. However, the Aitken mode $(<150 \mathrm{~nm})$ is something else, potentially an organic nitrogen species.

mode, indicating that mineral nitrates such as $\mathrm{NaNO}_{3}$ were responsible (Fig. 9). This is consistent with the IC analysis of the cascade impactors, which often showed significant $\mathrm{Na}^{+}$and $\mathrm{NO}_{3}^{-}$in the upper stages $\left(1.2<D_{a}<3.5\right.$ and $3.5<D_{a}<10 \mu \mathrm{m}$ ), and has also been seen in previous studies (e.g. Allan et al., 2004b; Topping et al., 2004). However, extra $m / z, 30$ signal was also occasionally observed in the Aitken mode, associated with organic signals seen during growth events, which is unlikely to be related to mineral nitrates, as sea salt and dust particulate matter is largely confined to the coarse mode. It is also unlikely to be $\mathrm{NH}_{4} \mathrm{NO}_{3}$, due to the lack of an $m / z 46$ signal. In this instance, it may be possible that the signal, instead of originating from inorganic nitrates, may instead arise from the fragmentation of organic nitrates (producing $\mathrm{NO}^{+}$) or amines (producing $\mathrm{CH}_{2} \mathrm{NH}_{2}^{+}$ 
or its isomers). While it is possible to have fragments of this $m / z$ originating from other organic species that do not contain nitrogen (e.g. $\mathrm{CH}_{2} \mathrm{O}^{+},{ }^{13} \mathrm{CCH}_{5}^{+}$), these are generally small features in the mass spectra relative to peaks such as 27 and 43, based on previous experience in both ambient sampling and laboratory work. Conversely, the $m / z 30$ signal was often found to be as large as the largest organic peak (43) during these measurements. The presence of excess submicron $m / z 30$ signal has been noted on previous occasions and correlations found with the organic fraction (Allan et al., 2004b; A. Middlebrook, NOAA Aeronomy Laboratory, Unpublished field data, 2002), although at this stage, it is very difficult to conclusively identify the species responsible with AMS data alone. This is discussed further below.

\section{Discussion}

The data from the AMS show that, as expected, the majority of the matter involved in the particle growth is organic in nature, within the measurement capabilities of the instrument. Limitations imposed by the low signal to noise ratios meant that only particle populations with mass modes of $D_{v a}$ values in the high tens of $\mathrm{nm}$ were observable, however signals at $m / z$ values associated with organic species were always the first detected during growth events. Note that, however, this in no way implies that organic species are involved in the initial nucleation itself. The nature of the organics is unlike any of those seen previously with the AMS in other environments. With the capabilities of the instrument, the signature was found to be invariant of whether an event day was Aitken or accumulation mode dominated, implying that the condensing species are the same regardless of the size of the particles they are condensing onto. This is an important result with reference to the rest of the chemical analyses taking place in the project, as it supports the assumption that any chemical species identified using bulk samples collected on filters or impactors are representative of those responsible for the growth of new particles specifically.

In an attempt to explain the unique mass spectral signature for the organic species encountered in this experiment, the chemical species identified through the offline analysis of filter pack and impactor samples collected at the site. In particular, the AMS mass spectra are consistent with the GCMS analysis of filter samples, which identified much of the organic mass as being alkanes. The most abundant alkanes also on non-polluted cases were in the range of C27-C29, which is taken to be indicative of biogenic sources of emission. Similar results were also obtained by the analyses of Shimmo et al. (2004), who also found significant amounts of alkanes, with the peak at carbon number 27. Note that this carbon number cannot be directly confirmed using the AMS mass spectral data, as laboratory data have shown the locations and relative sizes of the peaks within the mass spectra to be largely invariant as a function of alkane carbon number

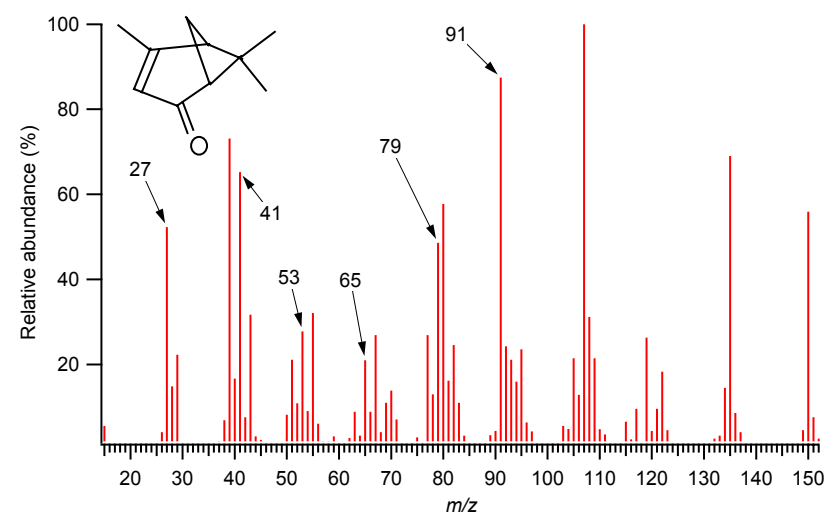

Fig. 10. Molecular structure and mass spectrum of verbenone, taken from the NIST database (2003). Some the unexpected peaks present in the ambient data are labelled. $m / z 39$ is not present in the AMS data shown previously, as it is routinely rejected due to interferences from thermally-ionised potassium. The listed higher mass fragments are also not present, but these are probably lost through the thermal effects described in Sect. 2.

above approximately $\mathrm{C} 10$ (although the absolute sizes still scale with mass, as expected). The significance of alkanes is not inconsistent with the CNR Bologna cascade impactor analyses from event days, which showed that an amount (approximately 50 to $80 \%$, depending on the sample) of the particulate matter in the lowest stage $\left(D_{a}<140 \mathrm{~nm}\right)$ could not be accounted for by IC or water soluble organic carbon analyses, implying a significant fraction was not water soluble.

The mechanism for how these species come to exist in the particle phase isn't entirely clear. Conceptually, they could have originally evaporated though the radiative heating of the tree surfaces before condensing onto the particle phase, however Marcolli et al. (2004) predict that the vapour pressures of alkanes of these lengths to be too low for them to be considered semivolatile at standard temperature and pressure. It must also be noted that if the constituents were semivolatile, there is a possibility that some of the ambient particulate mass may have been lost back to the gas phase in instrument sampling lines (which were generally warmer than ambient) or from the substrate during bulk sampling.

The oxidation products of monoterpenes and sesquiterpenes were also identified in the offline analyses, although some of the species could not easily be quantified due to their chemical instability. This is particularly interesting, because the $70 \mathrm{eV}$ EI mass spectrum of verbenone (an oxidised monoterpene, one of the specific species identified using GCMS) listed in the NIST database (2003) contains many of the peaks unaccounted for in the AMS spectrum such as $m / z 27$, 29, 51, 53, 65, 77, 79 and 91 (Fig. 10), while the molecular structure is indeed bicyclic and contains a double bond, as speculated above. None of the higher $m / z$ peaks listed in NIST, which include the base peak, appear in the AMS spectrum (e.g. $m / z$ 107, 135 and 150), but this is probably due to the thermal effects caused by the vaporiser, as mentioned 
in the introduction. However, even taking these into account, the relative abundances of carbon, hydrogen and oxygen are reflected in the fragments, so the emphasis seen here of the peaks towards those a few amu smaller than the aliphatic sequence could very well be indicative of a low hydrogen to carbon ratio, possibly due to terpene oxidation products. Note that this interpretation is by no means implying that the composition can be treated as a direct combination of verbenone and alkanes; the additional peaks noted are probably produced from a wide range of related species and it remains to be seen how representative verbenone (or any other identified species) is of that fraction. Also note that the relative abundances of the two categories cannot be inferred with these data at this stage because the ambient terpene oxidation products will be contributing to the alkane peaks to a degree, which is currently uncertain. As part of future work, a systematic laboratory study of verbenone and other related species using an AMS would be highly desirable.

In an attempt to see if there was a direct link between the particulate organics measured by the AMS and the suspected gas phase precursors, the measured organic particulate matter below $200 \mathrm{~nm} D_{v a}$ was compared with the total mixing ratio of gas phase monoterpene oxidation products, measured by MPIK Heidelberg using Chemical Ionisation Mass Spectrometry (Sellegri et al., 2005a, 2005b). While a distinct correlation was not evident (probably due to spatial and temporal mismatches between the formation of the precursors and organic particulate matter), it was found that there was never any measurable organic particles of these sizes when the measured gas mixing ratio was less than $500 \mathrm{ppt}$, showing that the Aitken mode particulate matter could not be formed in the precursors' absence.

Using Liquid Chromatography-MS on filter samples, Anttila et al. (2005) made the finding that there was an increase in the amounts of short-chain $n$-alkanoic acids in the particles phase during event days. Monocarboxylic acids tend to give a large signal at $m / z 43$ in the AMS (Alfarra, 2004; Silva et al., 2006 ${ }^{1}$ ) and as this is the base peak during growth events, the finding is not inconsistent with the results presented here. However, as stated previously, there are many potential contributors to this $m / z$, including alkanes, so it is difficult to say whether these species represent a significant fraction of the total organic mass or not.

As also stated previously, particulate amines have been observed at Hyytiälä previously in the form of dimethylamine (Mäkelä et al., 2001) and as stated before, the amine family of compounds could be responsible for the excess signal $m / z 30$ seen in the mass spectrum. According to the NIST database, dimethylamine does have a peak at $m / z$ 30, although it is a minor peak. Much larger peaks are expected at $m / z, 28$ and 40-45, but these could have been obscured by other species in the AMS data, including other organics and argon. Crucially, a peak of a similar size to $m / z 30$ is expected at 46 for dimethylamine, which is not present in the AMS data. Looking at other species, the library spectrum of methylamine does have $m / z, 30$ as its major peak, but also contains a large peak at $m / z 31$, which again was not found in the ambient data. What is interesting is that the higher alkylamine mass spectra listed by NIST, from propylamine onwards, consist of a very strong peak at $m / z 30$ with very little contribution from others, so this family might be a candidate.

If amines are indeed present, this may have implications for the nucleation and growth mechanisms. It is known that acids condense much faster in the presence of a base (Korhonen et al., 1999), which an amine could act as in the absence of ammonia in the early stages of growth. Conversely, it has also been shown that SOA formation can be promoted by acid-catalysed reactions (Jang and Kamens, 2001; Limbeck et al., 2003), processes that the presence of a base could suppress, in principle. The initial source of these species, however, is not immediately obvious.

However, the possibility that organic nitrates may be responsible for the rogue $m / z, 30$ signal has yet to be discounted, although recent technical developments should aid in investigating and quantifying this in the future. Based on the atomic weights of the respective elements (De Laeter et al., 2003), a mass spectrometer with a $m / \Delta m$ resolution of at least 800 would be required to separate the $\mathrm{CH}_{2} \mathrm{NH}_{2}^{+}$ and $\mathrm{NO}^{+}$peaks $(\Delta m$ is effectively unity in the current quadrupole mass spectrometer). At the time of writing, an AMS design fitted with a high resolution, orthogonal extraction (Chen et al., 1999), reflectron time-of-flight mass spectrometer (Tofwerk AG model H-TOF, Thun, Switzerland) is undergoing testing at Aerodyne Research and the University of Colorado at Boulder and early results are highly promising. This will also aid in resolving other cluttered peaks, especially $m / z 43$, as discussed above, in addition to the other benefits of using a time of flight mass spectrometer, such as capturing complete mass spectra of single particles and as a function of particle size (Drewnick et al., 2005). This will be the subject of future publications.

It is still interesting to note that the averaged organic mass spectral signature has, to date, not been clearly observed in any other environments, even in cases where it would be reasonable to expect regional biogenic SOA. It is possible that after the initial formation of the particulate matter, the organic species undergo subsequent transformations in the atmosphere through internal or heterogeneous reactions (Kalberer et al., 2004) or even cloud processing, so this particular signature may indeed never be distinctly seen far from the source. However, it may also be that this particular signal is being routinely dwarfed by the signals from anthropogenic SOA sources in other environments, as few other studies in pristine, biogenically-influenced sites have been performed to date. Indeed, mass spectra resembling the signature seen here have been extracted from some studies in remote, biogencially-influenced sites when other signatures are removed numerically (Worsnop et al., 2005), although this work is currently ongoing. 
During this campaign, the 'normal' oxidised organic spectrum (with $m / z 44$ as the base peak) dominated when the organic mass concentrations were high and the air originated from continental Europe, which is probably as a result of a large anthropogenic contribution. During some other periods influenced by continental airmasses (such as 10-11 April), a combination of the two spectra was observed, with peaks from both the regional oxidised organic spectrum and the growth event spectrum. Other evidence of biogenic species in the particle phase (e.g. pinic acid and other tracers) was also observed during these periods (Anttila et al., 2005; Cavalli et al., 2005; R. Janson, Stockholm University, personal communication, 2005), but it is not clear based on the observations alone at what stage these species entered the particle phase; whether they condensed onto the particles within the local forest itself or further upwind. This is something that requires further investigation.

\section{Conclusions}

An Aerodyne Aerosol Mass Spectrometer (AMS) was deployed as part of the suite of instrumentation used in the QUEST 2 intensive field study in Hyytiälä, Finland during March and April 2003. The object of the experiment was to study and quantify the particle formation events and the conditions surrounding them. It was able to study the dynamics of the growth processes and chemical compositions with high size and time resolutions.

The conditions that favoured nucleation events were northerly air masses, where the particle mass concentrations were low, and the particles mainly composed of sulphate with little ammonium. On occasions when the site was influenced by continental air masses, the particulate compositions were more indicative of processed regional emissions.

On the event days, the particles first appeared during the morning and grew throughout the day and into the night. As they accumulated mass, they became detectable with the AMS and a mass spectral signature was obtained. The particles were organic in nature during the majority of their growth stages, although they sometimes acquired some inorganic mass during the later stages. The mass spectral signature was unlike any seen previously in other environments but was consistent between different events and the size of the particles the species were condensing onto during the events themselves. The dominant peaks in the mass spectra seem to be in agreement with the theory that the condensing species consisted primarily of a combination of terpene oxidation products and alkanes from plant waxes. There is also evidence to suggest that a form of organic nitrogen, possibly amines, may also be present, although this requires further investigation.
Acknowledgements. This work was supported by the Nordic Centre of Excellence BACCI (Biosphere-Aerosol-Cloud-Climate Interactions). The AMS was purchased and maintained through UK Natural Environment Research Council (NERC) research grant GR3/12499. During part of this work, J. D. Allan was in receipt of NERC studentship NER/S/A/2000/03653. The filter analyses were supported by The Academy of Finland, project 48867. Library mass spectra were taken from the NIST Chemistry Webbook (http://webbook.nist.gov/chemistry/). Thanks to R. Janson (Stockholm University) for the OC, EC and organic acid data and F. Arnold (MPIK Heidelberg) for the CIMS data. Additional thanks to M. Canagaratna (Aerodyne Research Inc.) and J. Jimenez (University of Colorado at Boulder) for the AMS logging software support during the measurements.

Edited by: K. Hämeri

\section{References}

Aalto, P., Hämeri, K., Becker, E., Weber, R., Salm, J., Mäkelä, J. M., Hoell, C., O’Dowd, C. D., Karlsson, H., Hansson, H. C., Vakeva, M., Koponen, I. K., Buzorius, G., and Kulmala, M.: Physical characterization of aerosol particles during nucleation events, Tellus B, 53, 344-358, 2001.

Alfarra, M. R.: Insights Into Atmospheric Organic Aerosols Using An Aerosol Mass Spectrometer (PhD Thesis), Department of Chemical Engineering, UMIST, 2004.

Alfarra, M. R., Coe, H., Allan, J. D., Bower, K. N., Boudries, H., Canagaratna, M. R., Jimenez, J. L., Jayne, J. T., Garforth, A., Li, S., and Worsnop, D. R.: Characterization of urban and rural organic particulate in the Lower Fraser Valley using two Aerodyne Aerosol Mass Spectrometers, Atmos. Environ., 38, 5745-5758, 2004.

Allan, J. D., Jimenez, J. L., Williams, P. I., Alfarra, M. R., Bower, K. N., Jayne, J. T., Coe, H., and Worsnop, D. R.: Quantitative sampling using an Aerodyne aerosol mass spectrometer - 1 . Techniques of data interpretation and error analysis, J. Geophys. Res.-Atmos., 108, 4090, doi:10.1029/2002JD002358, 2003a

Allan, J. D., Alfarra, M. R., Bower, K. N., Williams, P. I., Gallagher, M. W., Jimenez, J. L., McDonald, A. G., Nemitz, E., Canagaratna, M. R., Jayne, J. T., Coe, H., and Worsnop, D. R.: Quantitative sampling using an Aerodyne aerosol mass spectrometer -2 . Measurements of fine particulate chemical composition in two U.K. cities, J. Geophys. Res.-Atmos., 108, 4091, doi:10.1029/2002JD002359, 2003b.

Allan, J. D.: An Aerosol Mass Spectrometer: Instrument Development, Data Analysis Techniques and Quantitative Atmospheric Particulate Measurements, PhD Thesis, Department of Physics, UMIST, 2004.

Allan, J. D., Coe, H., Bower, K. N., Alfarra, M. R., Delia, A. E., Jimenez, J. L., Middlebrook, A. M., Drewnick, F., Onasch, T. B., Canagaratna, M. R., Jayne, J. T., and Worsnop, D. R.: A generalised method for the extraction of chemically resolved mass spectra from Aerodyne aerosol mass spectrometer data, J. Aerosol. Sci., 35, 909-922, 2004a.

Allan, J. D., Bower, K. N., Coe, H., Boudries, H., Jayne, J. T., Canagaratna, M. R., Millet, D. B., Goldstein, A. H., Quinn, P. K., Weber, R. J., and Worsnop, D. R.: Submicron aerosol composition at Trinidad Head, California, during ITCT 2K2: Its rela- 
tionship with gas phase volatile organic carbon and assessment of instrument performance, J. Geophys. Res.-Atmos., 109, D23S24, doi:10.1029/2003JD004208, 2004b.

Anttila, P., Hyötyläinen, T., Heikkilä, A., Jussila, M., Finell, J., Kulmala, M., and Riekkola, M. L.: Determination of organic acids in aerosol particles from a coniferous forest by liquid chromatography-mass spectrometry, J. Sep. Sci., 28, 337-346, 2005.

Berner, A., Lurzer, C., Pohl, F., Preining, O., and Wagner, P.: Size distribution of the urban aerosol in Vienna, Sci. Total Environ., 13, 246-261, 1979.

Buzorius, G., Zelenyuk, A., Brechtel, F., and Imre, D.: Simultaneous determination of individual ambient particle size, hygroscopicity and composition, Geophys. Res. Lett., 29, 1974, doi:10.1029/2001GL014221, 2002.

Canagaratna, M. R., Jayne, J. T., Ghertner, D. A., Herndon, S., Shi, Q., Jimenez, J. L., Silva, P. J., Williams, P., Lanni, T., Drewnick, F., Demerjian, K. L., Kolb, C. E., and Worsnop, D. R.: Chase studies of particulate emissions from in-use New York City vehicles, Aerosol Sci. Technol., 38, 555-573, 2004.

Cavalli, F., Facchini, M. C., Decesari, S., Emblico, L., Mircea, M., Jensen, N. R., and Fuzzi, S.: Size-segregated aerosol chemical composition at a boreal site in southern Finland, during the QUEST project, Atmos. Chem. Phys. Discuss., 5, 8851-8877, 2005 ,

\section{SRef-ID: 1680-7375/acpd/2005-5-8851.}

Chen, Y. H., Gonin, M., Fuhrer, K., Dodonov, A., Su, C. S., and Wollnik, H.: Orthogonal electron impact source for a time-offlight mass spectrometer with high mass resolving power, Int. J. Mass Spectrom., 185-187, 221-226, 1999.

Cross, E., Onasch, T. B., Lewis, D. K., Jayne, J. T., Canagaratna, M. R., Worsnop, D. R., Dunlea, E., and Jimenez, J. L.: Characterization of Laboratory and Ambient Particles Using the Combination of Aerosol Mass Spectromtetry and Light Scattering Techniques, in 23rd Annual AAAR Conference, pp. 256 (8PE2), Hyatt Regency Atlanta, Atlanta, GA, 2004.

De Laeter, J. R., Bohlke, J. K., De Bievre, P., Hidaka, H., Peiser, H. S., Rosman, K. J. R., and Taylor, P. D. P.: Atomic weights of the elements: Review 2000 - (IUPAC technical report), Pure Appl. Chem., 75, 683-800, 2003.

DeCarlo, P. F., Slowik, J. G., Worsnop, D. R., Davidovits, P., and Jimenez, J. L.: Particle Morphology and Density Characterization by Combined Mobility and Aerodynamic Diameter Measurements. Part 1: Theory, Aerosol Sci. Technol., 38, 11851205, 2004.

Draxler, R. R. and Rolph, G. D.: HYSPLIT (HYbrid Single-Particle Lagrangian Integrated Trajectory) Model access via NOAA ARL READY Website: http://www.arl.noaa.gov/ready/hysplit4.html, NOAA Air Resources Laboratory, Silver Spring, MD, USA, 2003

Drewnick, F., Schwab, J. J., Hogrefe, O., Peters, S., Husain, L., Diamond, D., Weber, R., and Demerjian, K. L.: Intercomparison and evaluation of four semi-continuous PM2.5 sulfate instruments, Atmos. Environ., 37, 3335-3350, 2003.

Drewnick, F., Hings, S. S., DeCarlo, P., Jayne, J. T., Gonin, M., Fuhrer, K., Weimer, S., Jimenez, J. L., Demerjian, K. L., Borrmann, S., and Worsnop, D. R.: A New Time-of-Flight Aerosol Mass Spectrometer (TOF-AMS)-Instrument Description and First Field Deployment, Aerosol Sci. Technol., 39, 637-658,
2005.

Geller, M. D., Kim, S., Misra, C., Sioutas, C., Olson, B. A., and Marple, V. A.: A methodology for measuring size-dependent chemical composition of ultrafine particles, Aerosol Sci. Technol., 36, 748-762, 2002.

Huffman, J. A., Jayne, J. T., Drewnick, F., Aiken, A. C., Onasch, T., Worsnop, D. R., and Jimenez, J. L.: Design, Modeling, Optimization, and Experimental Tests of a Particle Beam Width Probe for the Aerodyne Aerosol Mass Spectrometer, Aerosol Sci. Technol., 39, 1143-1163, 2005.

Jang, M. S. and Kamens, R. M.: Characterization of secondary aerosol from the photooxidation of toluene in the presence of $\mathrm{NO}_{\mathrm{x}}$ and 1-propene, Environ. Sci. Technol., 35, 3626-3639, 2001.

Jayne, J. T., Leard, D. C., Zhang, X. F., Davidovits, P., Smith, K. A., Kolb, C. E., and Worsnop, D. R.: Development of an aerosol mass spectrometer for size and composition analysis of submicron particles, Aerosol Sci. Technol., 33, 49-70, 2000.

Jimenez, J. L., Jayne, J. T., Shi, Q., Kolb, C. E., Worsnop, D. R., Yourshaw, I., Seinfeld, J. H., Flagan, R. C., Zhang, X., Smith, K. A., Morris, J. W., and Davidovits, P.: Ambient aerosol sampling using the Aerodyne Aerosol Mass Spectrometer, J. Geophys. Res.-Atmos., 108, 8425, doi:10.1029/2001JD001213, 2003.

Kalberer, M., Paulsen, D., Sax, M., Steinbacher, M., Dommen, J., Prevot, A. S. H., Fisseha, R., Weingartner, E., Frankevich, V., Zenobi, R., and Baltensperger, U.: Identification of polymers as major components of atmospheric organic aerosols, Science, 303, 1659-1662, 2004.

Korhonen, P., Kulmala, M., Laaksonen, A., Viisanen, Y., McGraw, R., and Seinfeld, J. H.: Ternary nucleation of $\mathrm{H}_{2} \mathrm{SO}_{4}, \mathrm{NH}_{3}$, and $\mathrm{H}_{2} \mathrm{O}$ in the atmosphere, J. Geophys. Res.-Atmos., 104, $26349-$ 26353, 1999.

Kulmala, M., Pirjola, U., and Mäkelä, J. M.: Stable sulphate clusters as a source of new atmospheric particles, Nature, 404, 66-69, 2000.

Kulmala, M., Hämeri, K., Aalto, P. P., Mäkelä, J. M., Pirjola, L., Nilsson, E. D., Buzorius, G., Rannik, Ü., Dal Maso, M., Seidl, W., Hoffman, T., Janson, R., Hansson, H. C., Viisanen, Y., Laaksonen, A., and O'Dowd, C. D.: Overview of the international project on biogenic aerosol formation in the boreal forest (BIOFOR), Tellus B, 53, 324-343, 2001.

Kulmala, M.: How particles nucleate and grow, Science, 302, 10001001, 2003.

Kulmala, M., Laakso, L., Lehtinen, K. E. J., Riipinen, I., Dal Maso, M., Anttila, T., Kerminen, V. M., Hörrak, U., Vana, M., and Tammet, H.: Initial steps of aerosol growth, Atmos. Chem. Phys., 4, 2553-2560, 2004a,

SRef-ID: 1680-7324/acp/2004-4-2553.

Kulmala, M., Vehkamaki, H., Petajda, T., Dal Maso, M., Lauri, A., Kerminen, V. M., Birmili, W., and McMurry, P. H.: Formation and growth rates of ultrafine atmospheric particles: a review of observations, J. Aerosol. Sci., 35, 143-176, 2004b.

Limbeck, A., Kulmala, M., and Puxbaum, H.: Secondary organic aerosol formation in the atmosphere via heterogeneous reaction of gaseous isoprene on acidic particles, Geophys. Res. Lett., 30, 1996, doi:10.1029/2003GL017738, 2003.

Liu, P., Ziemann, P. J., Kittelson, D. B., and McMurry, P. H.: Generating Particle Beams of Controlled Dimensions and Divergence: I. Theory of Particle Motion in Aerodynamic Lenses and Nozzle 
Expansions, Aerosol Sci. Technol., 22, 293-313, 1995a.

Liu, P., Ziemann, P. J., Kittelson, D. B., and McMurry, P. H.: Generating Particle Beams of Controlled Dimensions and Divergence: II. Experimental Evaluation of Particle Motion in Aerodynamic Lenses and Nozzle Expansions, Aerosol Sci. Technol., 22, 314 324, 1995b.

Mäkelä, J. M., Yli-Koivisto, S., Hiltunen, V., Seidl, W., Swietlicki, E., Teinilä, K., Sillanpää, M., Koponen, I. K., Paatero, J., Rosman, K., and Hämeri, K.: Chemical composition of aerosol during particle formation events in boreal forest, Tellus B, 53, 380393, 2001.

Marcolli, C., Luo, B. P., Peter, T., and Wienhold, F. G.: Internal mixing of the organic aerosol by gas phase diffusion of semivolatile organic compounds, Atmos. Chem. Phys., 4, 2593 2599, 2004,

SRef-ID: 1680-7324/acp/2004-4-2593

McLafferty, F. W. and Turecek, F.: Interpretation of mass spectra, 4th edition, University Science Books, Mill Valley, CA, 1993

Nilsson, E. D., Paatero, J., and Boy, M.: Effects of air masses and synoptic weather on aerosol formation in the continental boundary layer, Tellus B, 53, 462-478, 2001.

NIST Mass Spec Data Center (Director S. E. Stein): Mass Spectra, in: NIST Chemistry WebBook, NIST Standard Reference Database Number 69, edited by: Linstrom, P. J. and Mallard, W. G., National Institute of Standards and Technology, Gaithersburg, MD, 2003.

Penner, J. E., Andreae, M., Annegarn, H., Barrie, L., Feichter, J., Hegg, D., Jayaraman, A., Leaitch, R., Murphy, D., Nganga, J., and Pitari, G.: Aerosols, their Direct and Indirect Effects, in: Climate Change 2001: The Scientific Basis. Contribution of Working Group I to the Third Assessment Report of the Intergovernmental Panel on Climate Change, edited by: Houghton, J. T., Ding, Y., Griggs, D. J., Noguer, M., van der Linden, P. J., Dai, X., Maskell, K. and Johnson, C. A., pp. 289-348, Cambridge University Press, Cambridge, New York, 2001.

Petäjä, T., Kerminen, V. M., Hämeri, K., Vaattovaara, P., Joutsensaari, J., Junkermann, W., Laaksonen, A., and Kulmala, M.: Effects of SO2 oxidation on ambient aerosol growth in water and ethanol vapours, Atmos. Chem. Phys., 5, 767-779, 2005,

\section{SRef-ID: 1680-7324/acp/2005-5-767.}

Rissanen, T., Hyötyläinen, T., Kallio, M., Kulmala, M., and Riekkola, M.: Characterization of organic compounds in aerosol particles from coniferous forest by GC-MS, Chemosphere, in press, 2006.

Sellegri, K., Hanke, M., Umann, B., Arnold, F., and Kulmala, M.: Measurements of organic gases during aerosol formation events in the boreal forest atmosphere during QUEST, Atmos. Chem. Phys., 5, 373-384, 2005a

SRef-ID: 1680-7324/acp/2005-5-373.
Sellegri, K., Umann, B., Hanke, M., and Arnold, F.: Deployment of a ground-based CIMS apparatus for the detection of organic gases in the boreal forest during the QUEST campaign, Atmos. Chem. Phys., 5, 357-372, 2005b,

SRef-ID: 1680-7324/acp/2005-5-357.

Shimmo, M., Jäntti, J., Aalto, P., Hartonen, K., Hyötyläinen, T., Kulmala, M., and Riekkola, M. L.: Characterisation of organic compounds in aerosol particles from a Finnish forest by on-line coupled supercritical fluid extraction-liquid chromatography-gas chromatography-mass spectrometry, Anal. Bioanal. Chem., 378, 1982-1990, 2004.

Smith, J. N., Moore, K. F., Eisele, F. L., Voisin, D., Ghimire, A. K., Sakurai, H., and McMurry, P. H.: Chemical composition of atmospheric nanoparticles during nucleation events in Atlanta, J. Geophys. Res.-Atmos., 110, D22S03, doi:10.1029/2005JD005912, 2005.

Topping, D. O., Coe, H., McFiggans, G. B., Burgess, R., Allan, J. D., Alfarra, M. R., Bower, K. N., Choularton, T. W., Decesari, S., and Facchini, M. C.: Aerosol chemical characteristics from sampling conducted on the island of Jeju, Korea during ACE Asia, Atmos. Environ., 38, 2111-2123, 2004.

Twomey, S.: The influence of pollution of the shortwave albedo of clouds, J. Atmos. Sci., 34, 1149-1152, 1977.

Worsnop, D., Northway, M., Jayne, J., Canagaratna, M., Onasch, T., Allan, J., Cubison, M., Coe, H., Jimenez, J., DeCarlo, P., Huffman, A., Zhang, Q., Cross, E., and Davidovits, P.: Overview Of Aerosol Mass Spectrometry At Chebogue Point During ICARTT 2004, in: 24th Annual AAAR Conference, pp. 131 (5A2), Hilton Austin, Austin, TX, USA, 2005.

Zhang, Q., Stanier, C. O., Canagaratna, M. R., Jayne, J. T., Worsnop, D. R., Pandis, S. N., and Jimenez, J. L.: Insights into the chemistry of new particle formation and growth events in Pittsburgh based on aerosol mass spectrometry, Environ. Sci. Technol., 38, 4797-4809, 2004a.

Zhang, Q., Alfarra, M. R., Worsnop, D. R., Allan, J. D., Coe, H., Canagaratna, M. R., and Jimenez, J. L.: Deconvolution and Quantification of Hydrocarbon-like and Oxygenated Organic Aerosols Based on Aerosol Mass Spectrometry, Environ. Sci. Technol., 39, 4938-4952, 2005.

Zhang, X. F., Smith, K. A., Worsnop, D. R., Jimenez, J., Jayne, J. T. and Kolb, C. E.: A numerical characterization of particle beam collimation by an aerodynamic lens-nozzle system: Part I. An individual lens or nozzle, Aerosol Sci. Technol., 36, 617-631, 2002.

Zhang, X. F., Smith, K. A., Worsnop, D. R., Jimenez, J. L., Jayne, J. T., Kolb, C. E., Morris, J., and Davidovits, P.: Numerical characterization of particle beam collimation: Part II - Integrated aerodynamic-lens-nozzle system, Aerosol Sci. Technol., 38, 619-638, 2004b. 